\title{
Life-course trajectory of frailty and its clinical applications: a narrative review
}

Tung Wai Auyeung ${ }^{1}$, MD, FHKAM (Med); SWJ Lee², MD, FRCP (London)

\begin{abstract}
Frailty is a condition indicating a reduced reserve in multiple systems and their disconnections. The whole body system cannot repair or recover by itself and may go into irreversible decline should interventions not be carried out early. This review discusses frailty in terms of the conceptual framework, pathophysiology, measurement and identification, lifecourse trajectory, and clinical application of assessment. It is anticipated that clinical application of the electronic frailty index expands to various specialties beyond geriatric medicine.
\end{abstract}

Key words: Frailty; Geriatric assessment; Physiopathology
Pok Oi Hospital \& Jockey Club Institute of Ageing, The Chinese University of Hong Kong

Alice Ho Miu Ling Nethersole Hospital and Jockey Club Institute of Ageing, The Chinese University of Hong Kong

Correspondence to: Dr Tung Wai Auyeung, Pok Oi Hospital \& Jockey Club Institute of Ageing, The Chinese University of Hong Kong.Email:auyeungtw@gmail.com

\section{INTRODUCTION}

In 1980, the World Health Organization (WHO) published a manual for classification of consequences of diseases into impairment, disability, and handicap. ${ }^{1}$ This is further revised in 2001 to become the International Classification of Functioning, Disability and Health (ICF), ${ }^{2}$ which provides a standard framework for describing health and healthrelated states. In ICF, 'functioning' encompasses all body functions, activities, and participation, whereas 'disability' comprises impairments, activity limitations, and participation restrictions. In addition, ICF describes how environmental factors affect functioning of an individual.

In 2001, the conceptual framework of frailty was proposed by two studies separately., ${ }^{3,4}$ This framework differs from ICF in that it does not describe body functioning or interactions with environmental factors; rather it focuses on how multiple comorbidities or continuous accumulation of deficits lead to disintegration of the compensatory capacity of body functions. Phenotypically, frailty is manifested as unintentional weight loss, reduced muscle strength, slowness, exhaustion, and inactivity, ${ }^{3}$ whereas clinically it is presented as classical geriatric syndromes. ${ }^{5}$ The frailty framework seems more suitable than IFC for older people. The difference between the two models can be illustrated by the following case scenarios: (1) A 30-year-old man has multiple sclerosis and is paraplegic. He can manage a self-propelled wheelchair. (2) An 80-year-old man has hypertension, diabetes mellitus, chronic lung disease, and chronic heart failure. He had a minor stroke and has mild cognitive decline. He can walk slowly. The IFC model aptly describes the problem of the younger patient, but the frailty model suits the older patient better, as the presence of multiple chronic diseases (comorbidities) is the rule rather than an exception in older people.

Frailty is common in late life. The prevalence of frailty in different studies varies widely from $4.0 \%$ to $59.1 \%{ }^{6}$ According to a systemic review, the overall weighted prevalence of frailty was $10.7 \%$ and more common in older women than men $(9.6 \%$ vs 5.2\%). ${ }^{6}$ In 3018 community-dwelling Hong Kong Chinese aged $\geq 65$ years, the prevalence was $9.8 \%$ in women and $6.0 \%$ in men. ${ }^{7}$ Frailty is more prevalent in women, but women were less likely to decline in frailty status than men. ${ }^{7}$ Hospitalisation, older age, previous stroke, lower cognitive function, diabetes, and osteoarthritis were associated with worsening or less improvement in frailty state transition, whereas 
higher socioeconomic status was protective against frailty. ${ }^{7}$

\section{CONCEPTUAL FRAMEWORK}

The phenotypical framework characterises frailty by weight loss, reduced muscle strength, slowness, exhaustion, and inactivity. ${ }^{3}$ Other framework perceives frailty as an accumulation of multiple deficits, which encompassed comorbidities, physical and cognitive impairment, psychosocial risk factors, and geriatric syndromes. ${ }^{4,5}$ There are similarities and differences between these two frameworks, while both emphasise on multiple deficits (comorbidities) and the progressive nature of the condition. The phenotypical description of frailty is epiphenomenal, and frailty is a pre-disability state and is reversible, ${ }^{3}$ whereas the aetiological perspective of frailty measures the number of deficits accumulated during the life course, and frailty is a spectrum ranging from robustness to severe disability and then death. ${ }^{4,5}$ The reversibility of frailty was reported in communitydwelling older adults in Hong Kong; the condition reverted from pre-frail to robust in $25 \%$ and from frail to pre-frail in $50 \%$ within 4 years. ${ }^{7}$

Frailty is a phenomenon of reduced resilience and reserve in old age, a condition that can be exemplified with the decline in function in face of a stressor such as a urinary tract infection. ${ }^{5}$ A robust individual may experience only a modest decline in function and recover fully and promptly. In contrast, a frail older adult may decline dramatically, and even worse, recovery may not take a considerably longer period. If these stressors occur repeatedly, the functional decline becomes progressive and irreversible., ${ }^{4,5}$

\section{PATHOPHYSIOLOGY}

The pathophysiology of frailty is a complex and multifactorial process. ${ }^{3}$ It starts with the interaction between genetic predisposition and environmental factors, followed by accumulation of multiple deficits at both molecular and cellular levels with ageing, and results in reduced physiological reserve in various organs. ${ }^{5}$ Multiple chronic diseases, coupled with physical inactivity, malnutrition, overexpression of the cytokine system, and decline of the neuroendocrine system will result in the dysregulation of the metabolic balance and the loss of the inter-connectivity of the whole body inter- related systems. ${ }^{3,5}$ Frailty will then be manifested as negative energy balance, muscle loss and weakness, intolerance to exertion, and inactivity. ${ }^{3}$ Clinically, it may present as falls, delirium, and incontinence, the classical geriatric triad, at a time of stress. ${ }^{5}$ The outcome is poor, with recurrent hospital admissions, increased risk of institutionalisation, and mortality. ${ }^{5}$

\section{MEASUREMENT AND IDENTIFICATION}

Frailty can be measured in five dimensions: shrinkage, weakness, exhaustion, slowness, and low activity. ${ }^{3}$ It can also be measured quantitatively using the frailty index, ${ }^{8}$ which is equal to the number of deficits divided by the total number of health variables measured. Other frailty measurement tools include the FRAIL Scale, ${ }^{9}$ the Clinical Frailty Scale, ${ }^{8}$ the Edmonton Frail Scale ${ }^{10}$ the Tilburg Frailty Indicator, ${ }_{1}^{11}$ and the Groningen Frailty Indicator. ${ }^{12} \mathrm{~A}$ Hong Kong study reported that either gait speed or handgrip strength can be used to identify frailty with high sensitivity and specificity. ${ }^{13}$ The optimal tool depends on the purpose of frailty identification, the availability of equipment, and staff expertise.

The National Health Service of the United Kingdom developed an electronic frailty index by extracting health variables from primary care health database. ${ }^{14} \mathrm{~A}$ similar initiative is underway in the Hospital Authority of Hong Kong; a group of geriatricians and statisticians selected suitable health parameters readily available in the Clinical Management System to develop a Hong Kong version of an electronic frailty index. Every patient older than 60 years will have a real-time electronic frailty index to guide clinical management. However, an electronic frailty index lacks external compensation as a vital domain in the care of older people, as illustrated in the ICF model.

\section{COMPREHENSIVE GERIATRIC ASSESSMENT}

Comprehensive geriatric assessment (CGA) is an interdisciplinary diagnostic process to assess patients in various dimensions (medical, psychological, social, and functional) to formulate a coordinated and integrated plan for treatment and long-term care. ${ }^{15}$ Although frailty assessment is not intended for diagnostic purposes, some of the scales do comprise elements of CGA. For example, the Edmonton 
Scale, ${ }^{10}$ apart from the functional and physical measurements, also briefly assesses cognitive, mood, continence, and medication management, which are standard elements in CGA. In addition, the Tilburg Indicators $^{11}$ also covers hearing, vision, memory, psychological conditions, and social support. Some frailty assessment scales can be used as a quick screening CGA.

\section{LIFE-COURSE TRAJECTORY}

Life begins as embryos with identical phenotypes but different genotypes. Resilience (reversal of frailty) peaks at youth and starts to decline in midlife and throughout late life. Because of genetic and environmental influences, the differences between individuals widens over the entire life course. This difference in resilience may be modest in midlife but can vary widely in late life (FIGURE IA). The population variation of frailty index can shed light on how this variation behaves at the final stage of life. Variability of frailty index among people with early-stage Alzheimer's disease is wide; the severity and multiplicity of other comorbid conditions may vary widely. ${ }^{4}$ However, with progression of the neurodegeneration and the accumulation of other multiple deficits superimposed on the disintegration of the compensatory capacity across various body

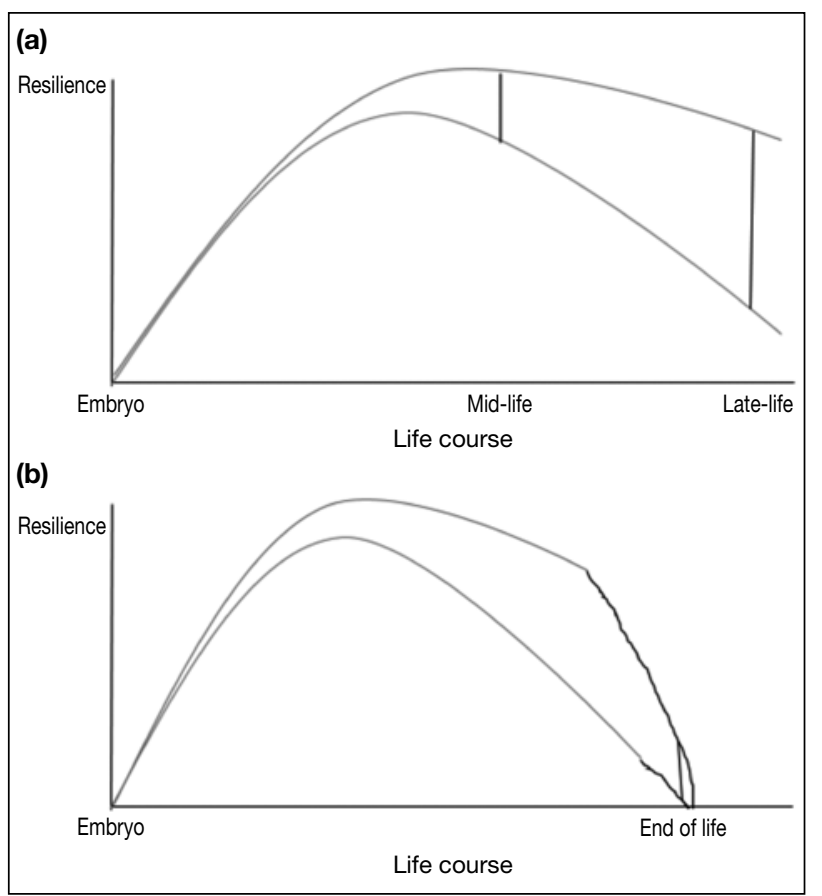

Figure. (a) Incomplete and (b) complete life-course trajectory of frailty of two individuals. systems, the diversity converges at the end stage of frailty. This phenomenon is also observed in persons with late-stage Alzheimer's disease. ${ }^{4}$ The standard deviation of frailty index in patients with late-stage Alzheimer's disease diminishes, and the mean of frailty index converges to the value of 0.4 , which represents the uniform and high frailty level. ${ }^{4}$ The life-course trajectory of resilience (reversal of frailty) is of homogeneity at the embryo stage and of heterogeneity at late-life stage and returns back to homogeneity at end-of-life stage (FIGURE 1B).

\section{HOMOGENEOUS PHENOTYPE AT THE END-STAGE OF LIFE}

If a person survives long enough to accumulate the maximum amount of deficits that a human can withstand, a phenotype commonly encountered in any geriatric healthcare settings is a patient who is uncommunicable, bed-bound, tube-fed, with joint contractures and pressure injury. As various chronic diseases (with different complications and presentations) progress and accumulate, the final common pathway is the same.

The advancement of Alzheimer's disease across various stages can demonstrate this life-course frailty trajectory and the regression to a single phenotype at the terminal stage of a chronic disease. The Functional Assessment Staging describes the entire course of Alzheimer's disease from incipient (stage 1) to advanced stage (stage 7f) ${ }^{16}$ resembling the reversal of child development into adulthood (TABLE). Each stage can mirror a stage of child development at a specific age. After childhood, individuals will follow different maturation and degeneration trajectories. The last stage of Alzheimer's disease (stage 7f) is the regression stage resembling infancy, which is a homogenous phenotype, corresponding to the terminal end of the life-course frailty trajectory. Alzheimer's disease advancement course demonstrates how frailty variation evolves from heterogeneity (stage 1) to homogeneity (stage 7f). Understanding the life-course trajectory frailty and its diversity in a population is the pre-requisite in its clinical applications.

\section{CLINICAL APPLICATION OF FRAILTY ASSESSMENT}

Frailty is associated with adverse health outcomes, 


\begin{tabular}{lcc}
\multicolumn{2}{c}{$\begin{array}{c}\text { TABLE } \\
\text { Child Development Stage and Functional Assessment } \\
\text { Staging for Alzheimer's disease }\end{array}$} \\
\hline $\begin{array}{l}\text { Child } \\
\text { development } \\
\text { stage }\end{array}$ & $\begin{array}{c}\text { Gained or lost } \\
\text { ability }\end{array}$ & $\begin{array}{c}\text { Functional } \\
\text { Assessment Staging } \\
\text { for Alzheimer's disease }\end{array}$ \\
\hline $12+$ y & Hold a job & 3 (incipient) \\
$8-12$ y & Simple finance & 4 (mild) \\
$5-7$ y & Select clothes & 5 (moderate) \\
5 y & Dressing & $6 a$ \\
4 y & Bathing & $6 b$ \\
4 y & Toileting & $6 \mathrm{c}$ \\
3 y & Urinary control & $6 \mathrm{~d}$ \\
$2-3$ y & Bowel control & $6 \mathrm{e}$ \\
$15 \mathrm{mo}$ & Speak 5-6 words & $7 \mathrm{a}$ \\
$12 \mathrm{mo}$ & Speak one word & $7 \mathrm{~b}$ \\
$12 \mathrm{mo}$ & Walking & $7 \mathrm{c}$ \\
$6-10 \mathrm{mo}$ & Sitting up & $7 \mathrm{~d}$ \\
$2-4 \mathrm{mo}$ & Smile & $7 \mathrm{e}$ \\
$1-3 \mathrm{mo}$ & Head up & $7 \mathrm{f}$ \\
\hline & &
\end{tabular}

including recurrent hospitalisation, utilisation of health resources, risk of institutionalisation, and mortality. ${ }^{5}$ Therefore, frailty can be a predictor for general health outcome, and its applications can be extended to:

(1) Treatment target in chronic disease management: In late-life, the diversity of resilience is large and tolerance to interventions can vary widely. To achieve the maximal risk-benefit ratio, a personalised treatment target should be made according to the frailty status of individuals. This strategy is well established in the guidelines and position statements about glycaemic control in older adults. Treatment targets are set according to the frailty status of individuals. ${ }^{17,18}$ In a Hong Kong consensus statement about glycaemic control, the target $\mathrm{Hba} 1 \mathrm{c}$ can vary from as stringent as a common adult $\mathrm{Hba1c}$ level of $8.5 \%$ for a very frail older adult, and even as liberal as with no specified target when close to end of life. ${ }^{19}$

(2) Advance care planning at end of life: Individualised care planning is recognised in hospice for cancer patients whose needs are diversified owing to physical, functional, cultural, religious, and spiritual belief differences. Terminal cancer stage is not equivalent to advanced frailty. Cancer can be terminal without much accumulation of deficits in various systems. In the Clinical Frailty Scale, patients with terminal cancer with life expectancy of $<6$ months is classified separately under category 9 without daily functioning consideration. Variation in resilience level in cancer patients is wide even when the life expectancy is $<6$ months. Terminal cancer can accelerate frailty progression. Frail older people at the terminal end of the frailty trajectory are similar in phenotype. Since 2015, the Hospital Authority's Community Geriatric Assessment Service that oversee the healthcare of residents in old age homes has implemented the end-of-life care programme. A standardised advance care planning inventory was developed, and common care needs are generally covered. At the start, some health professionals were sceptical about using a uniform, rather than a personal approach, in end-of-life care. However, these residents are at the terminal end of the life-course frailty trajectory and share a similar phenotype and care needs. Therefore, a uniform approach in end-of-life care is appropriate, efficient, and effective. What matters is the family's values about death and dying, to which health professionals have to address by an individualised approach.

(3) Direct patient journeys across different healthcare settings: Healthcare utilisation rate accelerates with ageing, in particular for hospitalisation need. The accident and emergency department is a convenient portal for older patients to seek medical or even social support. The complexity of their medicosocial needs is a challenge to the emergency medicine doctors. Admission to the acute care setting offers an easy solution but adds a burden to the already overcrowded and highly occupied acute medical wards. This situation is worse during the winter surge seasons. Some hospitals in Hong Kong have initiated collaboration between emergency room service and geriatricians to reduce hospitalisation. Frailty assessment has been used to triage patients to various service sectors, including convalescence hospital, geriatric day hospital, fast track transitional care in old age home and community social and personal care support services. However, this service model still awaits evaluation to determine whether it is efficient and cost-effective.

(4) Risk stratification and treatment selection in surgery: Frailty can predict surgical outcomes 
and healthcare utilisation. ${ }^{20-23}$ It is used to stratify operation risk and advise surgeons and patients on treatment options to achieve the highest riskbenefit ratio. In cardiac surgery, conventional risk stratification scores, ${ }^{24,25}$ which comprises mostly cardiac or other physiological parameters, have been used to predict cardiac surgical outcomes. The addition of frailty assessment increases the accuracy of prediction of outcomes. ${ }^{26,27}$ The missing link is the functional assessment in frailty. ${ }^{28}$ Frailty assessment should not be used to deny older patients from appropriate treatment. ${ }^{26}$ Rather, it should be used to distinguish robust older patients who can benefit more from standard invasive treatment. ${ }^{26}$ The 4 -item Essential Frailty Toolset ${ }^{29}$ (chair-stand test, cognitive function, haemoglobin level, and albumin level) can identify older patients who can benefit more from surgical valvular replacement rather than transcatheter aortic valve replacement when the score is $\leq 3$.

(5) Weight maintenance and muscle preservation: Unintentional weight loss and reduced muscle strength are two cardinal features of frailty syndrome. ${ }^{3}$ Being modestly overweight and even centrally obese confers survival benefit in old age. ${ }^{30-32}$ Sarcopenia is associated with adverse health outcomes. ${ }^{33}$ Therefore, weight maintenance together with muscle preservation is key in the management of frailty. To date, there is no effective pharmacological treatment for both conditions. Adequate nutrition, in particular protein intake, together with resistive muscle exercise remain the mainstay of treatment. ${ }^{34}$

\section{CONCLUSION}

Frailty is a condition indicating a reduced reserve in multiple systems and their disconnections. The whole body system cannot repair or recover by itself and may go into irreversible decline should interventions not carried out early. Frailty assessments can predict adverse health outcomes However, measurement and clinical application of frailty are not widely practised. It is anticipated that clinical application of the electronic frailty index expands to various specialties beyond geriatric medicine. Nonetheless, validation and evaluation of the electronic frailty index is needed in various diseases, for different purposes, and in different healthcare settings.

\section{REFERENCES}

1. World Health Organization. International Classification of Impairments, Disabilities, and Handicaps: a Manual of Classification Relating to the Consequences of Disease. 1980.

2. World Health Organization. International Classification of Functioning, Disability and Health: 2001.

3. Fried LP, Tangen CM, Walston J, Newman AB, Hirsch C, Gottdiener J, et al. Frailty in older adults: evidence for a phenotype. J Gerontol A Biol Sci Med Sci 2001;56:M146-56. Crossref

4. Mitnitski AB, Mogilner AJ, Rockwood K. Accumulation of deficits as a proxy measure of aging. ScientificWorldJournal 2001;1:32336. Crossref

5. Clegg A, Young J, Iliffe S, Rikkert MO, Rockwood K. Frailty in elderly people. Lancet 2013;381:752-62. Crossref

6. Collard RM, Boter H, Schoevers RA, Oude Voshaar RC. Prevalence of frailty in community-dwelling older persons: a systematic review. J Am Geriatr Soc 2012;60:1487-92. Crossref

7. Lee JS, Auyeung TW, Leung J, KwokT, Woo J.Transitions in frailty states among community-living older adults and their associated factors. J Am Med Dir Assoc 2014;15:281-6. Crossref

8. Rockwood K, Song X, MacKnight C, Bergman H, Hogan DB, McDowell I, et al. A global clinical measure of fitness and frailty in elderly people. CMAJ 2005;173:489-95. Crossref

9. Morley JE, Malmstrom TK, Miller DK. A simple frailty questionnaire (FRAIL) predicts outcomes in middle aged African Americans. J Nutr Health Aging 2012;16:601-8. Crossref

10. Rolfson DB, Majumdar SR, Tsuyuki RT, Tahir A, Rockwood K. Validity and reliability of the Edmonton Frail Scale. Age Ageing 2006;35:526-9. Crossref

11. Gobbens RJ, van Assen MA, Luijkx KG, Wijnen-Sponselee MT, Schols JM. The Tilburg Frailty Indicator: psychometric properties. J Am Med Dir Assoc 2010;11:344-55. Crossref

12. Peters LL, Boter H, Buskens E, Slaets JP. Measurement properties of the Groningen Frailty Indicator in home-dwelling and institutionalized elderly people. J Am Med Dir Assoc 2012;13:54651. Crossref

13. Auyeung TW, Lee JS, Leung J, Kwok T, Woo J. The selection of a screening test for frailty identification in community-dwelling older adults. J Nutr Health Aging 2014;18:199-203. Crossref

14. Clegg A, Bates C, Young J, Ryan R, Nichols L, Teale EA, et al. Development and validation of an electronic frailty index using routine primary care electronic health record data. Age Ageing 2016;45:353-60. Crossref

15. Rubenstein LZ, Stuck AE, Siu AL, Wieland D. Impacts of geriatric evaluation and management programs on defined outcomes: overview of the evidence. JAm Geriatr Soc 1991;39:8S-18S. Crossref

16. Reisberg B. Functional assessment staging (FAST). Psychopharmacol Bull 1988;24:653-9. Crossref

17. Sinclair AJ, Abdelhafiz AH, Rodríguez-Mañas L. Frailty and sarcopenia: newly emerging and high impact complications of diabetes. J Diabetes Complications 2017;31:1465-73. Crossref

18. Kirkman MS, BriscoeVJ, Clark N, Florez H, Haas LB, Halter JB, et al. Diabetes in older adults: a consensus report. J Am Geriatr Soc 2012;60:2342-56. Crossref

19. Wong CW, Lee JS, Tam KF, Hung HF, So WY, Shum CK, et al. Diabetes in older people: position statement of The Hong Kong Geriatrics Society and the Hong Kong Society of Endocrinology, Metabolism and Reproduction. Hong Kong Med J 2017;23:52433. Crossref

20. Makary MA, Segev DL, Pronovost PJ, Syin D, Bandeen-Roche K, Patel $\mathrm{P}$, et al. Frailty as a predictor of surgical outcomes in older patients. J Am Coll Surg 2010;210:901-8. Crossref

21. Reisinger KW, van Vugt JL, Tegels JJ, Snijders C, Hulsewé KW, Hoofwijk AG, et al. Functional compromise reflected by sarcopenia, frailty, and nutritional depletion predicts adverse 
postoperative outcome after colorectal cancer surgery. Ann Surg 2015;261:345-52. Crossref

22. Robinson TN, Wu DS, Stiegmann GV, Moss M. Frailty predicts increased hospital and six-month healthcare cost following colorectal surgery in older adults. Am J Surg 2011;202:5114. Crossref

23. Hewitt J, Moug SJ, Middleton M, Chakrabarti M, Stechman MJ, McCarthy K, et al. Prevalence of frailty and its association with mortality in general surgery. Am J Surg 2015;209:254-9. Crossref

24. Nashef SA, Roques F, Michel P, Gauducheau E, Lemeshow S, Salamon R, et al. European system for cardiac operative risk evaluation (EuroSCORE). Eur J Cardiothorac Surg 1999;16:913. Crossref

25. Jin R, Furnary AP, Fine SC, Blackstone EH, Grunkemeier GL. Using Society of Thoracic Surgeons risk models for risk-adjusting cardiac surgery results. Ann Thorac Surg 2010;89:677-82. Crossref

26. Afilalo J, Alexander KP, Mack MJ, Maurer MS, Green P, Allen LA, et al. Frailty assessment in the cardiovascular care of older adults. J Am Coll Cardiol 2014;63:747-62. Crossref

27. Sepehri A, Beggs T, Hassan A, Rigatto C, Shaw-Daigle C, Tangri N, et al. The impact of frailty on outcomes after cardiac surgery: a systematic review. J Thorac Cardiovasc Surg 2014;148:31107. Crossref

28. Chikwe J, Adams DH. Frailty: the missing element in predicting operative mortality. Semin Thorac Cardiovasc Surg 2010;22:10910. Crossref

29. Afilalo J, Lauck S, Kim DH, LefèvreT, Piazza N, Lachapelle K, et al. Frailty in older adults undergoing aortic valve replacement: the FRAILTY-AVR study. J Am Coll Cardiol 2017;70:689-700. Crossref

30. Auyeung TW, Lee JS, Leung J, Kwok T, Leung PC, Woo J. Survival in older men may benefit from being slightly overweight and centrally obese: a 5-year follow-up study in 4,000 older adults using DXA. J Gerontol A Bio Sci Med Sci 2010;65:99-104. Crossref

31. Lee JS, Auyeung TW, Chau PP, Hui E, Chan F, Chi I, Woo J. Obesity can benefit survival: a 9-year prospective study in 1614 Chinese nursing home residents. J Am Med Dir Assoc 2014;15:3428. Crossref

32. Lee JS, Auyeung TW, Kwok T, Li M, Leung J, Woo J. Survival benefit of abdominal adiposity: a 6-year follow-up study with Dual X-ray absorptiometry in 3,978 older adults. Age (Dordr) 2012;34:597-608. Crossref

33. Beaudart C, Zaaria M, Pasleau F, Reginster JY, Bruyère O. Health outcomes of sarcopenia: a systematic review and meta-analysis. PloS One 2017;12:e0169548. Crossref

34. Beaudart C, Dawson A, Shaw SC, Harvey NC, Kanis JA, Binkley N, et al. Nutrition and physical activity in the prevention and treatment of sarcopenia: systematic review. Osteoporos Int 2017;28:1817-33. Crossref 